Eixo Temático: Formação Profissional do Biólogo

ET-02-003

\title{
CONQUISTANDO CONHECIMENTO NO CONTATO COM A NATUREZA: EXPERIÊNCIA DOS PIBIDIANOS DE CIÊNCIAS BIOLÓGICAS EM AULA DE CAMPO COM ESCOLARES DO ENSINO FUNDAMENTAL DO MUNICÍPIO DE ALAGOINHAS-BA
}

Hilton Fernandes Bastos Junior ${ }^{1}$; Jorge Ailton Araujo Carvalho ${ }^{1}$; Lindaura Laís da Silva ${ }^{1}$; Maria José Dias Sales²; Eltamara Souza da Conceição ${ }^{3}$

${ }^{1}$ Bolsistas de iniciação à docência do Programa de Iniciação à Docência - PIBID/UNEB E-mail: hilton_junior_12@hotmail.com; bio.jcarvalho@yahoo.com.br; lais.silva.15@hotmail.com.

${ }^{2}$ Supervisora do Programa de Iniciação à Docência - PIBID/UNEB. E-mail: maria_uneb@yahoo.com.br).

${ }^{3}$ Coordenadora de Área do Programa de Iniciação à Docência - PIBID/UNEB. E-mail: elta_mara@yahoo.com.br.

http://dx.doi.org/10.21472/congrebio2016.et-02-003

\section{RESUMO}

Atividades extraclasse, como as de campo, sãoferramentasrelevantes para auxiliar o educador nas suas aulas. Para que o ensino permita a apropriação do conhecimentopelos aprendentes, é necessário o engajamento entre a classe e o educador e este tipo de atividade possibilita.O Programa Institucional de Bolsa de Iniciação a Docência (PIBID) tem viabilizado vivências fora dos padrões pré-estabelecidos nas aulas habituais e tem agregado experiências diversasà formação profissional dos bolsistas-ID, superando os problemas gerados pelo ensino tradicional. A aula de campo proporciona maior dinamismo às aulas, ao serem trabalhados conteúdos de Ciências. Foi percorrida uma trilha num fragmento de Mata ombrófila densa, no Complexo UNEB-EBDA, Campus II, da Universidade do Estado da Bahia (UNEB). Este foi feito pelos aprendentes do $7^{\circ}, 8^{\circ}$ e $9^{\circ}$ anos, do Colégio Estadual dos Rodoviários, sob orientação dos bolsistas ID do subprojeto interdisciplinar Biologia/Matemática do Departamento de Ciências Exatas e da Terra, Campus II, UNEB, em Alagoinhas e da professora regente. A meta era observar o ambiente natural e avaliar as interações ecológicas que ocorrem nos ecossistemas e em contrapartida, verificar vestígios de antropização no fragmento, o qual se encontra em estágio de regeneração. Assim, os aprendentes mantiveram contato com a natureza, se apropriando dos conteúdos trabalhados, numa atividade prazerosa e ao mesmo tempo rica em conhecimento. O objetivo foi alcançado, uma vez que estes mostraram interesse, motivação ao aprender, verificado pelas discussões sobre o conteúdo durante a experiência e a forma como interagiam entre si, com os pibidanos e a docente, demonstrando o significado para eles, da experiência vivenciada e do conteúdo trabalhado.

Palavras-chave: PIBID; Aula de Campo; Ecologia.

\section{INTRODUÇÃO}

O Programa Institucional de Bolsa de Iniciação a Docência tem viabilizado uma diversidade de vivências aos bolsistas ID, o que vem agregando experiências impares, tanto para a formação profissionaldestes, quanto paramelhoria da relação e da apropriação do conhecimento pelos aprendentes que estes atendem e para os professores nas escolas onde funciona.Apesar de ser cada vez mais difundida a ideia de que experiências práticas e de campo 
agregam valores ao ensino de Ciências, nem sempre é adotada nas aulas, cotidianamente ou as são, mas de forma inadequada. Este tipo de experiência permite ao pibidiano, como professor em formação, reiterar esses conceitose refletir melhor quanto à incorporação desse tipo de prática ao ensino de Ciência, o que corrobora positivamente o incremento na sua qualificação, para além do que contém o currículo de graduação.

De modo geral, os conteúdos relacionados à Educação Ambiental e à Ecologia permeiam amplamente os programas curriculares das classes do ensino fundamental. No entanto, esses conteúdos são trabalhados em aulas teóricas tradicionais, conceituais, em sala de aula. Muitas vezes isso se deve à falta de estrutura nas escolas para dispor de logística suficiente para realizar atividades de campo, mas muitas vezes por deficiente formação do educador, que não tem experiências que permitam criar formas de estruturar essas atividades extraclasse.

As aulas de campo possibilitam aapropriação do conhecimento porque permite a comprovação destes, na prática, através de problemas suscitados durante a sua realização ou evidências que permitem a comprovação das questões abordadas em sala de aula, no campo. Isso facilita a aprendizagem nas ciências naturais. FREIRE (1996) aponta que é fundamental diminuir a distância entre o que se diz e o que se faz, de tal forma que, num dado momento, a fala seja a prática. Gonçalves (1990), cita que a educação ambiental diferencia-se da educação tradicional por preocupar-se não apenas com conceitos, mas também com valores.Os educandos e educadores se deparam com o que é abordado em sala e há uma percepção realista, o que permite ter uma visão critica a respeito do assunto tratado.

\section{OBJETIVO}

O objetivo deste trabalho consistiu em, através de atividades extraclasse, aprimorar a compreensão dos bolsistasID sobre a aplicação de conteúdos dados em sala de aula em ambientes adequados à sua contextualização, conquistando novas experiênciasna área da educação, enriquecendo a sua formação.

\section{METODOLOGIA}

Os educandos se deslocaram da Escola Estadual dos Rodoviários, situando bairro Pirinel, em Alagoinhas-BA, em um ônibus que os levaram até a Universidade do Estado da Bahia, Campus II. Foram 32 educandos, dois educadores e dois funcionários da instituição.Os Bolsistas ID, juntamente com a docente das turmas, organizaram uma trilha no fragmento de Mata ombrófila densa, em regeneração, da UNEB, fomentando os objetivos a seguir: percepção do espaço natural; interações planta-invertebrados-meio e diversidade de plantas em distintos ecossistemas. O tema central a ser abordado na atividade foi: A importância da manutenção e conservação do meio ambiente e influência da urbanização/antropização sobre os ecossistemas naturais. A cada observação feita, houve a abordagem sobre os principais conteúdos de ecologia e meio ambiente, trabalhados previamente em sala de aula, para que houvesse uma associação clara entre a teoria e a prática.

\section{RESULTADOS E DISCUSSÃO}

Em consenso, os bolsistas ID consideraram a aula de campo como umarelevanteatividade para consolidação da aprendizagem pelos educandos. Constatando-se uma aula mais dinâmica, motivadora, agradável e mais interessante para os alunos. Observou-se que, a maioria dos estudantes redobrava sua atenção a cada uma das explicações dadas e também foram geradas muitas questões, por eles apresentadas. Desta forma, percebeu-se a receptividade dos educandos quanto à atividade proposta, que muitas vezes não se observa em sala de aula. Santos (2002) cita as contribuições da aula de campo de Ciências e Biologiaem ambiente natural, como positivas na aprendizagem dos conceitos, na medida em quefuncionam como um estímulo para os professores, como uma possibilidade de inovação para seus 
trabalhos, por isso se empenham mais na orientação dos educandos. Assim, a motivação mútua permite, portanto, a efetivação dos objetivos traçados na aplicação da aula extraclasse.Pinheiro (2006), afirma que:

O ambiente e o homem, inseridos na paisagem, revelam informações que são vistas e sentidas na relação de uso e interação. De um lado estão as características do ambiente, com formas e sentidos; de outro o indivíduo que vê, sente ou percebe a sua volta sob prismas/valores culturais, vivos, carregados de significados.

A percepção dos bolsistasID diante da atividade foi vista como uma quebra de paradigmas. Uma nova forma de interagir com os aprendentes, que por sua vez passaram a se expressar sem restrição ou receio nenhum suas ideias e suas atitudessob aquilo que estava sendo abordado. Ao longo da atividade, a educadorafez diversos questionamentos e a maioria deles foram respondidos.

O local do trabalho favoreceu a atividade, pois o fragmento de mata do complexo UNEB-EBDA dispõe ainda de uma vasta área de mata, de uma mata ciliar e o Rio Catu. Foi possível discutir questões relevantes a cerca da antropização da área e de seu processo de recuperação. Uma das situações, por exemplo, verificadas no rio foi a eutrofização, devido à matéria orgânica despejada pelo esgotoque possibilitaa proliferação de algas e outros organismos e gera um impacto negativo. Mas, em contrapartida também foi evidenciada a importância ecológica da área, que pode se transformar em área de conservação. Sendo considerada como um dos últimos remanescentes de mata do município, habilitada para 0 desenvolvimento de ações de educação ambiental e de pesquisas na área de Biologia.

O trabalho foi relevante também por corroborarpara a aproximação dos discentes, do ensino fundamental e médio, do meio acadêmico. Gerando condições para criação de perspectivas diferentes em relação à geração do conhecimento. O interesse dos educando foi grande quando foram visitados os laboratórios de pesquisa na universidade. Segundo Silva et al. (2010):

A análise do mundo não fica no sensocomum, aos poucos o professor trabalha cada etapa até que esse vínculo que o aluno tem com o "achismo", seja rompido definitivamente, e o aluno esteja preparado para assumir-se como observador do objeto e transformador de sua realidade.

Assim que os pibidianos entenderam a importância dessa atividade para promover a ressignificação de conceitos e ideias que os educandos tinham sobre os fenômenos estudados durante a visita à universidade.

O bolsistaID,durante a caminhada com os aprendentes e experiência na visita aos laboratórios, para além do que se aprende no dia-a-dia nos componentes curriculares da área pedagógica, por meio da vivência e observação do comportamento dos aprendentes e da postura do educador, o que muito colabora para sua qualificação profissional.

Expandir o ambiente de aprendizado, tanto dos estudantes quanto dos bolsistasID, permitiu uma relação mais íntima e compíscua com o objeto de estudo, bem como permitiu a reflexão sobre as questões sociais, ambientais e comportamentais, que uma atividade desta natureza propõe. Marinho (2004) cita que:

[...] acreditando que as mudanças de atitudes e comportamentos serão obtidas por meio da educação, sendo a escola um espaço social privilegiado a contribuir para que tais mudanças aconteçam e, que a consciência ambiental é também uma construção social, nesse contexto o papel da educação ambiental torna-se mais do que relevante - torna-se primordial.

Assim, os pibidianos entenderam que a atividade, além de possibilitar ampliação do conhecimento sobre o conteúdo já citado acima, cumpriu o papel de educar ambientalmente os 
educandos, perante os problemas ambientais específicos do seu município e sobre a repercussão disso nas questões ambientais globais.

Enfim, essa experiência foi vista pelos pibidianos como uma forma mais fácil de abordagem dos conteúdos trabalhados, aliando-se a teoriaà prática, como tem sido bastante difundido, é algo bastante salutar para aprendizagem dos educandos.

\section{CONCLUSÃO}

A atividade foi considerada relavante e satisfatória para a promoção do conhecimento, melhoria das relações entre discentes, docentes e pibidianos e para fundamentar e sensibilizar sobre questões-chaves de educação ambiental, que apenas o contato com a natureza permite realizar plenamente.

\section{AGRADECIMENTOS}

Agradecemos a CAPES por conceder as bolsas de ID e de Coordenação de Área e possibilitar a realização desta pesquisa e experiência. À Universidade do Estado da Bahia e à Escola Estadual dos Rodoviários, por permitirem ao pibidiano mais experiências no futuro campo de trabalho.

\section{REFERÊNCIAS}

FREIRE, P. Pedagogia da autonomia: saberes e necessários à prática educativa. São Paulo: Paz e Terra, 1996. (Coleção Leitura).

GONÇALVES, D. R. P. A Educação Ambiental e o ensino básico. In: SEMINÁRIO NACIONAL SOBRE UNIVERSIDADE E MEIO AMBIENTE, 4., 1990, Florianópolis. Textos Básicos. Florianópolis: [s.n], 1990. p.125-146.

MARINHO, A. M. S. A Educação ambiental e o desafio da interdisciplinaridade. Belo Horizonte: PUC - Minas Gerais, 2004. (Dissertação de Mestrado).

PINHEIRO, E. S. Percepção ambiental e atividade turística no Parque Estadual do Guartelá Tibagi-PR. R. RA'E GA, Curitiba, n. 12, p. 121-134, 2006.

SANTOS, S. A. M. A excursão como recurso didático no ensino de biologia e educação ambiental. In: VIII ENCONTRO PERSPECTIVAS DO ENSINO DE BIOLOGIA, 6, 2002, São Paulo. Anais... São Paulo: FEUSP, 2002.

SILVA, A. M. R. Trabalho de campo: prática andante de fazer Geografia. Disponível em: <http://www.educacaopublica.rj.gov.br/biblioteca/geografia/geo03d.htm>. Acesso em: 29 abr. 2016. 